\title{
El Convenio tripartito como garantía del derecho a la información de los trabajadores traspasados en un proceso de fusión
}

\author{
Rosa Cecilia Fuentes Alarcón ${ }^{1}$
}

\author{
INFORMACIÓN DEL ARTÍCULO RESUMEN
}

\section{Historia del artículo:}

Recibido el 28 de diciembre de 2020 En la presente investigación se desarrolla el derecho a la información de los Aceptado el 30 de diciembre de 2020 trabajadores que son traspasados a consecuencia del proceso de fusión. Del análisis realizado se muestra que los trabajadores traspasados se encuentran desprotegidos frente a la fusión respecto al derecho a la información. Se

\section{Palabras claves:}

Fusión

Traspaso de trabajadores

Derecho a la información

Derechos laborales

Convenio tripartito concluye proponiendo modificaciones en la Ley General de Sociedades peruana con la finalidad de proteger el derecho a la libertad de información de los trabajadores; $y$, se aconseja como mecanismo jurídico- empresarial al convenio tripartito.

The tripartite agreement as a guarantee of the right to information of the workers transferred in a merger process

\section{ABSTRACT}

\section{Keywords:}

Merger

Transfer of workers

Right to information

Labor rights

Tripartite agreement.
This research develops the right to information of the workers who are transferred as a result of the merger process. From the analysis carried out we can realize that the transferred workers are unprotected in front of the merger regarding the right to information. It concludes by proposing modifications to the peruvian General Law of Companies in order to protect the workers' right to freedom of information; and the tripartite agreement is suggested as a legalbusiness mechanism.

\section{Introducción}

La fusión societaria como forma de reorganización trae como consecuencia que las sociedades pierdan la personalidad jurídica para concentrarse en una nueva o existente trasladando su patrimonio en "bloque" a la sociedad fusionante (absorbente o creada). Una de las consecuencias de la fusión empresarial es el traslado de los trabajadores a la empresa fusionante, quien acepta las relaciones laborales vigentes haciéndolas suyas. Al respecto, ni en la Ley General de Sociedades ni en la legislación laboral, se especifica el tratamiento a las deudas laborales que resultan un pasivo de la empresa fusionada; además, no se señala en el proceso de fusión la participación de los trabajadores para salvaguarda de su derecho a la información; entre otras cuestiones, sobre la asunción de responsabilidad por adeudos laborales o sobre la protección frente al despido arbitrario.

La situación descrita permite afirmar que existe una necesidad emergente de los trabajadores traspasados, pues se encuentran en una situación de desventaja

${ }^{1}$ Investigador independiente, Abogada. Email: rosafuentes0610@gmail.com. ORCID: https://orcid.org/0000-0002-2045-7935 
respecto a su nuevo empleador, debido a que no lo eligen ni conocen, encontrándose en la necesidad de aceptar el cambio ya que la remuneración es el medio básico para su subsistencia económica tanto individual como familiar (de ser el caso). Además, el panorama para ellos no resulta claro toda vez que existe falta de información en el proceso de fusión; por lo que, no reconocen a quién deben exigir las acreencias laborales; existiendo, en algunos casos, incertidumbre respecto a quién (empresa absorbente, incorporante, absorbida, incorporada) es el obligado frente al trabajador.

La problemática descrita líneas arriba se puede concretar en la siguiente interrogante ¿Cómo se debe proteger el derecho a la información y los derechos laborales con contenido económico de los trabajadores traspasados en un proceso de fusión? Con la finalidad de dilucidar la problemática se plantea como objetivo general, determinar el mecanismo de protección de los derechos laborales con contenido económico y el derecho a la información de los trabajadores traspasados a través de un proceso de fusión societaria. Se propone al convenio tripartito como mecanismos jurídico-empresarial de protección de los derechos laborales con contenido económico y modificaciones al procedimiento de fusión en cuanto a la información brindada a los trabajadores.

Esta investigación se justifica porque permite proponer normas mínimas para generar seguridad laboral a los trabajadores que son parte de un traspaso, acerca de la exigibilidad de los derechos laborales con contenido económico que adquirieron en la relación laboral y su protección al derecho a la información en el proceso de fusión. En ese sentido, la propuesta de la celebración opcional de un convenio laboral tripartito beneficiaría al empleador primigenio, al nuevo empleador y a los trabajadores al negociar internamente los derechos laborales con contenido económico disponibles de acuerdo con el marco legal actual. Asimismo, la modificación del proceso de fusión de los artículos referentes al derecho a la información de los trabajadores inmersos en un proceso de fusión sería considerada un avance para el efectivo derecho a la información de los trabajadores inmersos en un proceso de fusión.

\section{La fusión societaria como expresión de la libertad empresarial y su relación con el principio de continuidad}

\subsection{La fusión empresarial en el ordenamiento jurídico peruano}

La fusión empresarial como fenómeno jurídico y económico se ha desarrollado en la historia de forma paulatina. En palabras de Morales (1991), la fusión es "la concentración de empresas en un solo titular, que se presenta vinculada a la consolidación de la gran empresa" (p. 185). En el mismo sentido, Espinoza (2014) señala que la fusión se desarrolla "cuando se reúnen dos o más personas jurídicas para formar una sola" ( $p$. 184). La fusión es una institución propia del derecho de las personas jurídicas caracterizada por implicar la unificación de dos o más personas jurídicas en una sola. En la misma línea, Montoya (2004) la define como "un acto en virtud del cual dos o más sociedades, previa disolución de alguna o de todas ellas, unen sus patrimonios, agrupando a sus respectivos socios en una sola sociedad" (p. 369). A efectos del presente artículo se entenderá a la fusión como aquel fenómeno económico recogido por el ordenamiento jurídico mediante el que dos o más sociedades unifican sus patrimonios, socios y relaciones jurídicas.

Respecto a las características esenciales de la fusión, Elías (2015) señala:

(i) La transmisión en bloque y a título universal, de los patrimonios de las personas jurídicas que se extinguen; (ii) la creación, como resultado de cualquier fusión, de un nuevo organismo social que, en su conjunto resultante, es enteramente nuevo, como forma acabada del vínculo entre las sociedades que participan en la fusión; y (iii) la extinción de la personalidad jurídica de las sociedades absorbidas o incorporadas. (p. 405)

En referencia a la primera característica, se sostiene que en el supuesto específico de las fusiones (...) siempre encontramos una transmisión, de la integridad de todos y cada uno de los patrimonios, en bloque y a titulo universal (Elías, 2015). En relación con la segunda característica se afirma que en la fusión se crea un organismo social enteramente nuevo, como forma acabada del vínculo de las sociedades que participan en la fusión. Referente a la tercera característica, se sostiene que la personalidad jurídica de las sociedades absorbidas o incorporadas se extingue.

Según el artículo 344 de la LGS, son formas de fusión societaria: 1) La fusión de dos o más sociedades para constituir una nueva sociedad incorporante; o, 2) La absorción de una o más sociedades por otra sociedad existente

Finalmente, Elías (2015) señala como ventaja económica y social de la fusión, entre otras, la reducción de costos y procesos productivos ya que permite la eliminación total de las estructuras jurídicas de varias sociedades (...). Sin ánimo de desmerecer las ventajas de la fusión en la realidad económica, es necesario 
aterrizar el concepto de persona jurídica ya que es la base sobre la cual se permite la creación de sociedad; y, en consecuencia, el fenómeno de la concentración empresarial realizada mediante la fusión. Respecto a la persona jurídica, esta puede ser utilizada fraudulentamente con el fin de eludir el cumplimiento de obligaciones legales o contractuales, o deberes familiares o tributarios (Ormeño, 2006).

Además, es relevante para la investigación mencionar que, en la fusión, se produce una real transferencia de la empresa, pues se sustituye al titular de una unidad productiva, transfiriéndose bienes y personal. En este proceso se requiere la concurrencia del elemento objetivo - se transmite en bloque el patrimonio que incluye los elementos materiales necesarios para continuar con el negocio - y el elemento subjetivo - se produce transfiriéndosele a una persona jurídica distinta - (Toyama, 2015). Esta transferencia producirá que el cambio de empresario sea real.

Por último, la fusión empresarial es una forma de reorganización empresarial válida que genera como consecuencia la transmisión de la empresa, y a la vez un traspaso de todas las relaciones jurídicas, incluyendo las laborales. Esta última es tratada como si fuese cualquier otra relación jurídica; sin embargo, en el presente artículo se analiza si debe tratársele de forma diferente teniendo en cuenta su carácter alimentario.

\subsection{El Principio de continuidad en la relación laboral afectada por un traspaso debido a la fusión}

\subsubsection{Principio de continuidad en el Derecho al Trabajo.}

El núcleo fundamental del derecho al trabajo está compuesto por el libre ingreso a un puesto de trabajo (en caso sea un asalariado) o al mercado (en caso sea un independiente), sin barreras ni desigualdades; la salida del trabajador ya sea asalariado o independiente; $y$, finalmente, en caso ser trabajador dependiente a la estabilidad en su contrato laboral y a no ser privado del trabajo sin que medie causa justa.

Este derecho al trabajo puede verse afectado, en la realidad, por otro derecho reconocido a favor de quien realiza actividad empresarial, el derecho a a libertad de empresa. Rojas (2015) afirma que existe un problema en la realidad entre la libertad de empresa y el derecho al trabajo; incidiendo en que las sociedades organizadas como personas jurídicas al momento de hacer uso de su facultad organizativa se reorganizan o forman grupos de empresas; situación ante la cual el trabajador asalariado se encuentra desprotegido.

Sobre el particular, Toyama (2015), manifiesta que el Derecho del Trabajo evidencia constantes situaciones de conflicto de intereses entre empleador y trabajador, entre ellas, la reestructuración empresarial (entiéndase que dentro de este fenómeno económico - jurídico se encuentra la posibilidad legal de fusionar personas jurídicas), puesto que, por un lado, el trabajador dependiente - quiere que la relación laboral permanezca en el tiempo bajo las mismas condiciones (o mejore) y que sus créditos laborales estén debidamente garantizados; mientras que, el empleador, pretende mantener (o mejorar) la capacidad productiva, adoptando para ello las medidas y ajustes necesarios. Cabe resaltar que, Toyama (2015) hace referencia al conflicto de intereses y no al conflicto de derechos; asimismo, en el mencionado conflicto considera solo al trabajador asalariado y no al independiente, siendo aquél relevante para el Derecho Laboral.

Conforme se ha señalado, la libertad de empresa en su manifestación organizativa le brindaba al empresario la posibilidad de maximizar sus recursos y ganancias; ante ello, es el Estado quien - cubriendo la dimensión objetiva del derecho fundamental a la libertad de empresa - positiviza el proceso de fusión empresarial. En este proceso se permite a la sociedad absorbida o incorporada pasar en bloque y a título universal su patrimonio a la empresa incorporante o absorbente; entiéndase, además que, dentro del patrimonio se encuentran los activos y pasivos de la empresa, incluyéndose los adeudos laborales. Sin embargo, este adeudo no es de carácter convencional, es uno de carácter alimentario - laboral (entiéndase de antemano que la relación jurídico laboral es distinta a cualquier otra relación jurídica civil, razón por la que tanto en el ordenamiento jurídico internacional como nacional su protección es diferente).

En esta situación, diverge la válida y aceptada manifestación de la libertad de empresa en su dimensión organizativa a través del proceso de fusión empresarial y el derecho del trabajador a la continuidad de su relación laboral (en caso sea despedido), a conocer las condiciones del contrato laboral 
(entiéndanse que se tendrá un nuevo empleador, inclusive podrían cambiarse ciertas condiciones del contrato) y se genera discusión respecto al tiempo de servicios prestado y los beneficios adquiridos en relación a su antiguo y nuevo empleador en correspondencia a los derechos laborales con contenido económico (que para este punto es necesario analizar si la relación laboral continua o si por el contrario nos encontramos ante una nueva).

Aparece en juego el principio de continuidad como una herramienta fundamental a tener en cuenta en situaciones como las narradas previamente. Medina (2016) citando a Américo Plá señala que:

Para comprender este principio debemos partir de la base de que el contrato de trabajo es un contrato de tracto sucesivo, o sea, que la relación laboral no se agota mediante la realización instantánea de cierto acto, sino que dura en el tiempo. (p. 132)

Teniendo como base que la relación laboral es una de tracto sucesivo, se entiende su duración en el tiempo y el fundamento del principio en cuestión. Así pues, el principio de continuidad es reconocido tanto en el ámbito internacional como nacional, en palabras de Plá Rodriuez citado por Agreda (2010), este supone "la tendencia de atribuirle a la relación laboral la duración o permanencia más larga posible, desde cualquier punto de vista y en todos los aspectos" (p. 219).

Respecto a la aplicación del principio de continuidad en los efectos generados a los trabajadores traspasados debido a la transmisión de la empresa, Arce (2008) afirma que "el efecto general y único que se predica respecto de los cambios de titularidad en nuestro ordenamiento laboral es la subrogación del nuevo titular de la empresa en la posición contractual del precedente" (p. 147).

En la jurisprudencia nacional, la Corte Suprema en la Casación Laboral N¹3685-2013- La Libertad señaló que sólo si existen funciones y labores similares entre el puesto que ocupaba el trabajador en la empresa anterior y el (...) que ocupó en la siguiente empresa (...), operará la continuidad de la relación laboral, independientemente del nombre de la posición o puesto de trabajo en ambas empresas. Respecto al criterio asumido por la Corte, se discrepa ya que, el trabajador no decide cuál será su puesto de trabajo a ocupar, por lo que, no debería resultar perjudicado, contabilizándosele el tiempo de trabajo en su integridad.

De esta manera, en virtud del principio de continuidad, el vínculo laboral se mantiene vigente y permanece en el tiempo, incluso a pesar de que se produzcan modificaciones en la titularidad del empleador, como consecuencia de una reorganización societaria, como es el caso de la fusión.

\subsubsection{Relación laboral traspasada mediante la fusión, una aproximación al principio de continuidad y estabilidad del contrato laboral.}

Entiéndase a la relación jurídica laboral como aquella que emana de un contrato de trabajo (verbal o escrito). Es protegida de forma diferente a una relación jurídica de índole civil, debido a la desigualdad de poder de decisión y dirección que tiene uno de los sujetos (empleador) sobre el otro (trabajador); el trabajador depende económica e instrumentalmente del empleador y la remuneración (contraprestación recibida por el trabajador) tiene carácter alimentario.

El derecho al trabajo se manifiesta en la relación laboral en tres momentos: antes (el inicio de la relación laboral), durante (aumentos, beneficios adquiridos por convenios, entre otros) y después (extinción de la relación laboral con o sin causa justa). Por ello, se comparte lo afirmado por Neves (2003) cuando menciona que el contenido esencial del derecho al trabajo está comprendido por el derecho al trabajo de entrada - esto es facilitar el acceso al empleo a quienes no lo tienen - y el derecho al trabajo de salida permitiéndose conservarlo a quienes ya lo poseen. Esta última manifestación se puede ver afectada cuando se produce un proceso de fusión en el que el empleador es sustituido.

En el ordenamiento jurídico peruano hay dos supuestos de subrogación del empleador: primero, que se transfiera al trabajador mediante la figura de una cesión de posición contractual, y segundo, que se transfiera al trabajador en el marco de un proceso de reestructuración empresarial a través del mecanismo de transmisión de empresa (Arce, 2017, p. 104). Este 
último supuesto es el que aquí se analiza. Así pues, la fusión como forma de reestructuración patrimonial recogida en la LGS (1997) genera una modificación del empleador, en la misma que no es necesaria la opinión del trabajador.

Si bien actualmente no existe referencia normativa (laboral o comercial) a la subrogación contractual laboral o al destino de los trabajadores traspasados consecuencia de un proceso de fusión, se debe entender que, en atención al principio de continuidad, los derechos laborales de los trabajadores de la empresa comprendida en un proceso de fusión se encuentran debidamente resguardados pues el trabajador resulta completamente ajeno a los cambios que se puedan presentar en la organización empresarial o en la titularidad de la misma lo cual tiene que ver igualmente con el principio de despersonalización del empleador. En ese sentido, la organización empresarial que resulte del proceso de fusión asumirá la responsabilidad respecto a los derechos laborales de los trabajadores (Toledo \& Toledo, 2012, p. 4). Respecto a la relación laboral traspasada, bajo los principios de continuidad y estabilidad se afirma que la relación jurídica laboral subsiste.

En conclusión, si bien en el Perú no se ha regulado de forma expresa en la normativa comercial o laboral la subrogación del empleador en casos de modificaciones estructurales de sociedades mercantiles (como fusión, escisión, cesión de activos, entre otras); el principio de continuidad que irradia la relación laboral presupone que las relaciones laborales se encuentren protegidas frente a un posible despido motivado en la fusión puesto que, con la finalidad de que no se cause $u$ agravio injustificado al trabajador, considera que la relación laboral debe permanecer.

\subsubsection{Tiempo de servicios, ¿adquirido o por adquirir?}

El principio de continuidad evita que el contrato laboral se extinga o se vea interrumpido, prevaleciendo la relación laboral, su continuidad y su conservación. En palabras de Américo Plá, citado por Vera (2015) "ante una transferencia de trabajadores deberá considerarse toda la antigüedad generada por el trabajador, incluso desde el empleador primigenio" (p. 123). Asimismo, Vera (2015) afirma que (...) la relación de trabajo continuará bajo las directrices del nuevo empleador y los trabajadores acumularán el tiempo de servicios laborado para la empresa anterior, para todo efecto legal.

En el mismo sentido, Culqui (2015) afirma que la transmisión debería respetar las mismas condiciones laborales que mantenía el trabajador en la empresa anterior, a través del aseguramiento de la misma remuneración y la misma categoría profesional, pudiendo haber una mejora en las condiciones de trabajo, pero no un menoscabo en las mismas, evitando así que se utilice esta figura para evadir las normas laborales.

En el mismo sentido que Vera (2015) se sostiene que, dados los alcances del principio de continuidad, se debe admitir que en la relación laboral existe una resistencia a admitir la rescisión unilateral del contrato por voluntad patronal; por lo que se opta por la prolongación del contrato en casos de sustitución del empleador. En consecuencia, para determinar ciertos derechos (entiéndase derechos laborales con contenido económico) deberá contabilizarse todo el periodo laborado por el trabajador durante el vínculo laboral con ambas empresas.

En tal sentido, en lo que corresponda, deberá ser de aplicación el principio de continuidad, que supone que se deberá respetar la antigüedad y los derechos ya obtenidos por los trabajadores en función de esta (tal como comentaremos de modo específico en líneas posteriores). Dicho de otro modo, y para efectos prácticos, se comprende que la aplicación del principio de continuidad supone en casos como estos que ha habido una sola relación laboral, con todas las implicancias inherentes a ello pese a que, formalmente, se hayan configurado diferentes relaciones laborales.

\section{Convenio tripartito laboral y la protección del derecho a la información de los trabajadores inmersos en un proceso de fusión}

En este apartado se propone como método de solución jurídico - empresarial para los conflictos generados en un proceso de fusión al convenio tripartito. Para ello se analiza la relación del principio de continuidad con el convenio tripartito detallando los derechos salvaguardados por el principio de continuidad y la posibilidad de reducción o negociación basada en el 
principio de irrenunciabilidad. Posteriormente, se desarrolla el derecho a la información del trabajador inmerso en un proceso de fusión.

\subsection{El principio de continuidad laboral y el convenio tripartito laboral}

La disconformidad de los trabajadores ante los procesos de fusión empresarial es una realidad mundial que ha alcanzado titulares en diversos medios de comunicación de países como Corea, España e, incluso nuestro país, Perú.

En el presente apartado se busca esclarecer el objeto de estudio de la investigación. Para ello, se analizará la relación entre el principio de continuidad y el convenio tripartito, el mismo que se ofrece como propuesta de solución preventiva.

Las relaciones jurídicas se encuentran irradiadas por diversos principios. En específico, las de naturaleza laboral poseen principios propios como la irrenunciabilidad de derechos, continuidad, entre otros. En el presente acápite corresponde analizar si el principio de continuidad como tal sustenta al convenio tripartito o si este escapa de su influencia.

Para entender la afirmación antes acotada, debe quedar claro que la aplicación del principio de continuidad en los trabajadores traspasados se da de la siguiente manera: a) no serán despedidos a menos que exista causa justa, no siendo el proceso de fusión una causa de despido; b) debe gozar de los derechos laborales adquiridos (sea de forma legal o convencional); c) gozará del tiempo de servicios adquirido anterior a la fusión; y, d) deben ser respetadas sus condiciones de trabajo.

El principio de continuidad laboral "impone limitaciones tanto a la contratación temporal como al despido no justificado, ya que ese principio confluye con el de causalidad, en virtud del cual la duración del contrato debe ser garantizada mientras subsista la fuente que la originó" (Pacheco, 2015, p. 16). Así pues, de la aplicación del principio en estudio se aprecia que opera antes, durante y después de la relación laboral;

\footnotetext{
2 Pese a que el principio de continuidad señala que no se debe culminar la relación laboral ante una reorganización societaria ambas partes negocian y analizan los costos laborales que asumirán, muchas veces condicionando el despido de algunos trabajadores o
}

garantizando que su culminación se da únicamente cuando la fuente que originó el trabajo (empresa) desaparezca.

Es necesario especificar que la fuente que origina el trabajo subordinado, en esencia, es la empresa. Esta no debe ser confundida con el titular o empresario ya que son diferentes. Sánchez (2005) define al empresario como "la persona física o jurídica que profesionalmente y en nombre propio ejercita la actividad de organizar los elementos precisos para la producción de bienes o servicios para el mercado" (p.p. 99-100). Mientras que la empresa es "una unidad de producción en la que se combinan los precios del capital y del trabajo con la finalidad de suministrar al mercado" (p. 93). Por lo tanto, puede que la empresa cambie de titular o empresario, pero esta continúe; $y$, en consecuencia, la fuente de las relaciones laborales.

Aclarado ello, es necesario aterrizar los conceptos a la presente investigación teniendo en cuenta la aplicación del principio de continuidad en los casos de sustitución del empleador, a consecuencia de una fusión. Al respecto, Carrillo (2011), citando a Plá, señala que, "el principio de continuidad expresa el propósito de atribuirle la más larga duración a la relación laboral desde todos los puntos de vista y en todos los aspectos" (p.181), y es por eso que se le reconoce la siguiente proyección: (...) Prolongación del contrato en casos de sustitución del empleador.

Relacionando lo expuesto por Plá, tenemos que este principio confluye con el de causalidad, entendiéndose que pese a la transferencia de la empresa (fusión, adquisición o cualquier otra forma de reorganización societaria), al ser la unidad económica la misma, la relación laboral continúa.

Ahora bien, teniendo en cuenta el principio de continuidad laboral, se entiende que ante la interrogante de si ¿después de una fusión terminan las relaciones laborales de la empresa fusionada? La respuesta es negativa. En principio, no se debería despedir a ningún trabajador debido a una reorganización societaria ${ }^{2}$. Las relaciones jurídico -

analizando la forma en la cual se puede despedir sin acarrear costos elevados; todo ello a través de la técnica del "due diligence laboral". (Tsuboyama, 2014) 
laborales de la empresa fusionada son asumidas en bloque y a título universal por la empresa a fusionar, siendo así traspasados los trabajadores a la nueva empresa.

En todo caso, debe quedar establecido que el objeto de estudio del presente artículo son los trabajadores traspasados; esto es, aquellos que han sido trabajadores primigenios de las empresas a fusionar y que ahora son parte o de la sociedad absorbente o de la nueva sociedad (en concordancia con el principio de continuidad); dejándose fuera a aquellos trabajadores que son despedidos a consecuencia del proceso de fusión, muchas veces encajando tal situación en el artículo 52 inciso i) del D. Leg. $N^{\circ} 728$, en el cual se regula el cese colectivo.

Después de esclarecer la forma de aplicar el principio de continuidad en una reorganización societaria y teniendo en cuenta el proceso de fusión contemplado en la LGS, es coherente afirmar que los trabajadores traspasados, desconocen, mayoritariamente, sus derechos adquiridos, conservados y vigentes y quién es su actual empleador, debido a que la LGS no estipula como obligación de la sociedad informar a sus trabajadores del proceso; además de no regular el principio de continuidad o la figura jurídica del traspaso de trabajadores.

Por otro lado, la situación económica de las sociedades a fusionarse siempre será un dato relevante. Para ejemplificar tal afirmación debemos reflexionar acerca de la responsabilidad de las empresas parte de una fusión, el conocimiento que tienen los trabajadores traspasados previos a un proceso de fusión. Así pues, cuando la sociedad fusionante (absorbente o creada) cuenta con un estado financiero en pérdidas, ¿se trasladan sus deudas a la sociedad creada o absorbida? En cualquier caso, cuando cualquiera de las sociedades (fusionante o fusionada) no cuente con estabilidad económica, ¿quién asume las cargas laborales?

Como regla general, las cargas laborales deberán ser asumidas por "el nuevo empleador", ya que se transfiere en bloque patrimonial, el cual incluye activos y pasivos. Sin embargo, puede que este no reconozca todos los derechos ya adquiridos o que pese a reconocerlos no cuente con la suficiente solvencia económica para asumirlos. Por tanto, se justifica la actitud renuente del trabajador frente a la fusión de su empleadora, surgiéndole diversas dudas respecto al cobro real de su acreencia laboral. Como solución a la situación narrada se propone a la empresa absorbida que antes de fenecer asuma sus costos laborales o pacte la asunción de las deudas laborales con cierta parte de sus activos (por ejemplo, a través de un patrimonio fideicometido).

En el mismo sentido, Tsuboyama (2014) resalta la importancia de realizar en el proceso de fusión la auditoria laboral, también denominada due diligence laboral con la finalidad de que "los potenciales adquirentes conozcan cuáles son las contingencias o riesgos laborales que existen en la empresa que afrontarán una vez la hayan adquirido" (p. 260). Una vez realizada la auditoria laboral se establecerán los "costos laborales" y se tomarán las "medidas pertinentes" como la reducción de personal asumida por la empresa que desea fusionarse, negociaciones previas, entre otras. Estas medidas no siempre respetan los principios y derechos laborales; por ello, en la presente tesis se propone al convenio tripartito como medio para armonizar el derecho del trabajador y del empresario.

Quedando establecido quiénes son los trabajadores traspasados, y, que dentro del proceso de fusión no se exige a las sociedades informar a sus trabajadores ni se les permite oponerse a esta forma de reorganización empresarial; es lógico afirmar que los trabajadores carecen de la información necesaria para exigir, resguardar y proteger sus derechos (adquiridos o por adquirir) y conocer las condiciones de trabajo que muchas veces pueden ser modificadas a consecuencia de una fusión (ello se encuentra permitido por la facultad de dirección del empleador).

\section{Derecho de información de los trabajadores inmersos en un proceso de fusión.}

\subsection{Derecho a la información del trabajador}

Nuestra Constitución reconoce derechos fundamentales laborales específicamente a los trabajadores, a partir del artículo $22^{\circ}$. Asimismo, en su artículo $2^{\circ}$ recoge un listado numerus apertus de derechos fundamentales de toda persona. Ha quedado claramente determinado por la doctrina y la jurisprudencia que a los trabajadores se les reconocen 
los derechos fundamentales doblemente: como ciudadanos y como trabajadores. Ejemplos claros de derechos fundamentales que se aplican, tanto para las personas en general como para las personas inmersas en una relación laboral, es el derecho a la igualdad. Sin embargo, aquellos derechos les pertenecen por ser ciudadanos, no por ser trabajadores. Por lo tanto, son derechos laborales no exclusiva o específicamente laborales. (Pasco, 2012).

En síntesis, los derechos constitucionales laborales pueden ser específicos o inespecíficos (Pasco, 2012). Los primeros son aquellos que solo pueden darse en el contexto de una relación laboral. Por ejemplo, en la Constitución Mexicana de Quéretaro en 1917, la de Weimar en Alemania de 1919 y la de Perú de 1993 se reconoce como derechos laborales la libertad sindical, la negociación colectiva y la huelga. Por otro lado, los segundos, son aquellos derechos atribuidos con carácter general a los ciudadanos, que, al mismo tiempo, se desarrollan en la dinámica de la relación en el centro de trabajo.

Esta última subclase de derechos constitucionales laborales es de interés para el desarrollo del presente acápite toda vez que el derecho fundamental a obtener información sobre sus propios intereses es reconocido a todos los ciudadanos. Con la finalidad de sintetizar y analizar información se considera importante precisar conceptos básicos respecto al derecho fundamental a la información; y, luego, se relacione el mencionado con los trabajadores inmersos en un proceso de fusión.

Dentro de la Constitución peruana se encuentra reconocido como derecho fundamental en el artículo 2 inciso 4) la libertad de información por medio de cualquier comunicación social, sin previa autorización ni censura o impedimento alguno. En concordancia con el inciso a) del artículo 13 de la Convención Americana de Derechos Humanos (1978) en el cual se reconoce que:

Toda persona tiene derecho a la libertad de pensamiento y de expresión. Este derecho comprende la libertad de buscar, recibir y difundir informaciones e ideas de toda índole, sin consideración de fronteras, ya sea oralmente, por escrito o en forma impresa o artística, o por cualquier otro procedimiento de su elección.
El objeto del derecho a la información se encuentra situado en un plano objetivo, que no es otro que el de los hechos noticiables, pues "la información debe recaer, por tanto, en hechos o datos de la realidad"; es decir, que la noticia, o los hechos noticiables, o lo que puedan encerrar una trascendencia pública se constituyen en el objeto del derecho a la información" (Ortiz, 2017, p.540).

Respecto a las dimensiones de la libertad de información interesa la referida al "derecho de buscar o acceder a la información, que no sólo protege el derecho subjetivo de ser informado o de acceder a las fuentes de información, sino, al mismo tiempo, garantiza el derecho colectivo de ser informados, en forma veraz e imparcial" (Exp. N. 0905-2001-AA/TC, FJ.11).

Ahora bien, aterrizando al objeto de estudio se tiene que, en virtud del derecho constitucional laboral inespecífico a la libertad de información consagrado en nuestra Constitución, los trabajadores (individualmente u organizados en sindicatos) tienen el derecho - tal como cualquier ciudadano - de buscar, recibir y difundir información de toda índole verazmente, más aún si se trata de asuntos que atañen directamente a sus intereses como trabajadores.

Para entender el análisis siguiente se debe tener en cuenta a los trabajadores en los siguientes momentos: i) Los trabajadores inmersos en un proceso de fusión; es decir, antes de que sea la fecha de entrada en vigencia de la fusión que pactaron sus sociedades empleadoras en el acuerdo de fusión; y la inscripción de la Escritura Pública en Registros; en consecuencia, la extinción (de ser por absorción, la absorbida, si es por creación, ambas) o absorción a otra persona jurídica de su empleadora (cfr. Artículo 353, LGS); ii) Los trabajadores traspasados; es decir, aquellos que producto de la fusión han sido incorporados en una nueva o existente persona jurídica, continuando su relación laboral con la salvedad de haber sufrido su relación jurídica laboral la subrogación en la figura del empleador.

Respecto al primer momento, los trabajadores antes de la publicación de la convocatoria a los socios para la asamblea con el motivo de la fusión y la puesta a disposición de la información (detallada en el artículo 350) en el domicilio social a los socios, accionistas, 
obligacionistas y demás titulares de derechos de crédito o títulos especiales; no cuentan con ninguna posibilidad de informarse acerca de la existencia del proyecto.

En la normativa de la LGS antes reseñada sorprenden dos cuestiones: a) las formalidades en la información; b) los titulares del derecho a disponer de la información. Al respecto, se afirma que resulta insuficiente la puesta a disposición de la información relevante a la fusión y la situación económica de la empresa a los socios, accionistas, obligacionistas y demás titulares; pero, sobre todo, a los trabajadores; debido a que, "poner a disposición" significa que la persona jurídica debe tener a su alcance la información en caso de que sea solicitada por los sujetos mencionados en la LGS. Esto es inconsistente, pues los trabajadores desconocen la facultad con la que cuentan y la correcta lectura de la información brindada. Por otro lado, la información sólo será brindada en el domicilio social y no en otra ubicación, situación preocupante teniendo en cuenta que el domicilio social o consignado en el estatuto suele ser el centro de concentración de la sociedad, pero no el único local en el cual se labora.

En lo concerniente a los titulares del derecho a disponer de la información no se encuentran especificados los acreedores laborales; $y$, teniendo en cuenta que la LGS es una de naturaleza comercial, los acreedores serán entendidos en ese escenario; acreedores comerciales. Estos últimos son quienes, normalmente, realizan actos de comercio, es decir, "todo acto o hecho jurídico de interposición económica determinado por la especulación" (Montoya, 2004). En resumen, los sujetos denominados acreedores en la legislación comercial peruana se entienden, en principio, como aquellos que son parte de una relación jurídica comercial.

Teniendo en cuenta que, de acuerdo con la legislación nacional, no se realiza una comunicación directa y eficaz a los acreedores de las empresas inmersas en un proceso de fusión; $y$, que las formalidades en el proceso acerca de la información deben ser efectivas para los trabajadores; resulta inevitable preguntar si cacaso basta con poner a disposición la información para satisfacer el derecho a la libertad de información en la vertiente del acceso a la misma? ¿no resulta insuficiente señalar a los acreedores en términos genéricos, sin detallar un procedimiento específico y singular para los trabajadores de sociedades inmersas en el proceso de fusión? ¿Será necesario que las empresas empleadoras comuniquen directamente a sus trabajadores, ya sea de forma organizada (sindicatos) o individualmente del proceso de fusión y la información relevante para en su relación laboral?

Los trabajadores ostentan una relación jurídica especial y distinta al resto de personas, es tan importante la remuneración que perciben debido a su carácter indispensable y alimentario por lo que no sería equiparable a una relación comercial. La legislación debe acoplarse a la situación específica de los trabajadores inmersos en una fusión y a la inseguridad que ostentan estos en su relación. En ese sentido, se considera necesario que los trabajadores sean comunicados de forma directa, e, incluso, personal a través de una comunicación a reunión, de los cambios o posibles cambios en su relación jurídica como consecuencia del proceso de fusión ${ }^{3}$.

No basta con la puesta a disposición de la información, se considera que la normativa jurídica relativa a la fusión debe considerar dentro del proceso la obligación de las personas jurídicas inmersas en un proceso de fusión de comunicar a sus trabajadores el contenido de los documentos especificados en el artículo 350 de la LGS; $\mathrm{y}$, explicarles las posibles consecuencias en sus relaciones laborales.

La propuesta no trae consigo consecuencias negativas en la relación laboral ni en el clima laboral; por el contrario, al enterarse los trabajadores de la situación real podrá el empleador negociar con los trabajadores que, debido a situaciones propias de la fusión, no continuarán con su relación laboral, de ser el caso; o, por el contrario, podrían continuar con la relación laboral (traspaso), especificando y negociando los derechos y condiciones laborales. Asimismo, los trabajadores tendrían la facultad de negociar con

\footnotetext{
${ }^{3}$ Cabe resaltar que la postura asumida no merma la importancia de las acreencias mercantiles, simplemente, resalta la vital importancia de la acreencia laboral.
} 
conocimiento, ya sea de forma individual como colectiva sobre sus derechos laborales.

Respecto al segundo momento, esto es los trabajadores traspasados, conviene señalar que sus relaciones jurídicas laborales irradiadas por el principio de continuidad no han fenecido; sin embargo, puede que sus condiciones de trabajo se hayan modificado. Por lo tanto, los trabajadores traspasados consecuencia del proceso de fusión tienen la necesidad de encontrarse debidamente informados respecto a sus derechos laborales adquiridos y los posibles cambios en las condiciones laborales, incluso, en el mismo contrato laboral. En nuestra legislación no se concibe ninguna referencia a estos trabajadores, ni como puesta a disposición ni como facultad de los trabajadores. Resáltese que, en virtud del principio de irrenunciabilidad de derechos, los trabajadores no podrían disminuir sus condiciones laborales 0 remuneración; sin embargo, existen límites sobre los que sí se pueden negociar.

\subsection{Normativa Comparada}

En el Perú, el proceso de fusión y lo referente a este se encuentra regulado únicamente en la Ley General de Sociedades (1997) - legislación comercial - y se hace mención en la Ley de Relaciones Colectivas Laborales legislación laboral - respecto a la vigencia del convenio colectivo. En ninguna de estas leyes se concibe la obligación de las personas jurídicas de informar a los trabajadores de la fusión. Por ese motivo, resulta necesario desarrollar las facultades de contención que otorga nuestra legislación a los acreedores desprotegidos en el cobro efectivo de su acreencia.

Asimismo, la LGS en el artículo 350 señala como obligación dentro del proceso de fusión la puesta a disposición a sus socios, accionistas, obligacionistas y demás titulares de derechos de crédito o títulos especiales, en su domicilio social, los documentos relativos al: 1. El proyecto de fusión; 2. Estados financieros auditados del último ejercicio de las sociedades participantes. Aquellas que se hubiesen constituido en el mismo ejercicio en que se acuerda la fusión presentan un balance auditado cerrado al último día del mes previo al de la aprobación del proyecto de fusión; 3. El proyecto del pacto social y estatuto de la sociedad incorporante o de las modificaciones a los de la sociedad absorbente; y, 4. La relación de los principales accionistas, directores y administradores de las sociedades participantes. 5.- Derecho de los acreedores (en términos generales)

Esta información resulta insuficiente en cuanto al contenido e ineficaz respecto a la forma de comunicación. Téngase presente que, la relación laboral es una de subordinación y desigualdad de derechos, incluso dentro de la capacidad que tienen de conocer y procesar información calificada. Por ejemplo, los obreros de planta dedicados al manejo de máquinas industriales no cuentan con conocimientos previos en contabilidad, derecho, economía, etc., necesarios para entender el plan de fusión; a diferencia de un acreedor comercial, quien se entiende cuenta con conocimientos previos en las formas y posibilidades de cobrar sus acreencias debido a la característica de habitualidad.

En cuanto a la postura asumida, no se ataca ni desconocen los derechos constitucionales laborales de los empleadores, manifestados, por ejemplo, en la libertad de empresa, comercio, entre otras. Por el contrario, lo que se busca es armonizar las libertades y derechos tanto de empleadores como trabajadores. Por esta razón, las empresas tienen la plena libertad de reorganizar su patrimonio, personalidad jurídica y capital de la forma en la que consideren más beneficiosa para su productividad; siempre y cuando se respeten los derechos constitucionales laborales de los trabajadores, específicamente el derecho inespecífico a la libertad de información en la vertiente de recibirla de forma eficiente, eficaz y veraz.

Tal como lo expresa Goñi (2014):

La idea de vinculación del poder empresarial a los derechos fundamentales, llevando a cabo una operación de revisión radical de las líneas precedentes de interpretación judicial que consideraban la relación laboral como un ámbito, por esencia, privado, libremente construido por la exclusiva voluntad del empresario, sobre la libertad de organización y del poder de dirección y sustraído a los límites de los grandes derechos constitucionales. Con palabras que aún resuenan, el Tribunal Constitucional proclamó que la celebración de un contrato "no implica en modo alguno la privación para una de las partes, el trabajador, de los 
derechos que la Constitución le reconoce como ciudadano (p.6).

Como segundo punto de análisis en este apartado, corresponde cotejar las herramientas que confiere nuestra legislación, tanto a los acreedores comerciales como laborales.

Respecto a la fusión, la LGS protege a los acreedores, facultándolos a oponerse cuando su acreencia no se encuentre debidamente respaldada. Sin embargo, esta figura se reduce a los acreedores comerciales (artículos $219^{\circ}$ y $359^{\circ}$, LGS, 1997); teniendo en cuenta que la Ley que regula las fusiones es de naturaleza comercial, se entiende que cuando se refiere a acreedores lo hace únicamente respecto a los acreedores comerciales.

Por otro lado, en la legislación concursal se concibe la posibilidad de iniciar el proceso concursal a solicitud de los acreedores; siempre y cuando sus "créditos sean exigibles, se encuentren vencidos, no hayan sido pagados dentro de los treinta días calendario siguientes a su vencimiento y que, en conjunto, superen el equivalente a cincuenta Unidades Impositivas Tributarias vigentes a la fecha de presentación" (entiéndase que se necesita pluralidad de acreedores para solicitar el inicio del proceso concursal; sin embargo, de desistirse alguno de los solicitantes, luego de emplazado el deudor, no se impedirá la continuación del procedimiento) (Ley del Procedimiento Concursal, artículo $26^{\circ}$ ). Se entienden comprendidos tanto acreedores laborales como comerciales, muestra de ello es el artículo $40^{\circ}$ en el que se regula la relación de prelación establecida en el cobro de acreencias; además de la protección tuitiva de la ley al reconocer el principio de supremacía de la realidad.

Sin embargo, existen ciertos límites a la posibilidad del acreedor laboral de iniciar un proceso concursal, específicamente, a los que serán traspasados debido a que estos no cuentan, necesariamente, con el requisito de que la deuda se encuentre exigible, vencida, que no haya sido pagada dentro de los treinta días calendario siguientes a su vencimiento y que, en conjunto, superen el equivalente a cincuenta Unidades Impositivas Tributarias vigentes a la fecha de presentación. Tal afirmación debe entenderse cierta toda vez que los trabajadores traspasados no han disuelto su relación laboral; en consecuencia, su deuda es vigente; asimismo, resulta sumamente difícil contar con la suma de la acreencia establecida como requisito para iniciar proceso concursal; esto es, dos cientos diez mil soles (S/ $210,000.00)$

Por otro lado, en el país europeo la regulación del derecho a la información de los trabajadores inmersos en un proceso de fusión se aprecia desde dos vertientes: la ley laboral denominada "Estatuto de los Trabajadores" y la ley comercial N³/2009, de 3 de abril, sobre modificaciones estructurales de las sociedades comerciales (en adelante, LME); la misma que en el capítulo II hace referencia exclusiva al proceso de fusión de sociedades mercantiles.

Dentro de la LME se regula el derecho de los trabajadores a ser informados previamente a la fusión empresarial. Específicamente, el artículo 32 de la LME hace referencia a la obligación de publicidad que tienen las empresas inmersas en un proceso de fusión; así se establece que:

1. Los administradores están obligados a insertar el proyecto común de fusión en la página web de cada una de las sociedades que participan en la fusión, sin perjuicio de poder depositar voluntariamente un ejemplar del proyecto común de fusión en el Registro Mercantil correspondiente a cada una de las sociedades que participan en ella. El hecho de la inserción del proyecto de fusión en la página web se publicará de forma gratuita en el "Boletín Oficial del Registro Mercantil", con expresión de la página web en que figure y de la fecha de la inserción (...).

La inserción en la página web y la publicación de este hecho en el "Boletín Oficial del Registro Mercantil" deberán efectuarse con un mes de antelación, al menos, a la fecha prevista para la celebración de la junta general que haya de acordar la fusión. La inserción del proyecto de fusión en la página web deberá mantenerse hasta que finalice el plazo para el ejercicio por los acreedores del derecho de oposición a la fusión.

2. Si alguna de las sociedades que participan en la fusión careciera de página web, los administradores están obligados a depositar un ejemplar del proyecto común de fusión en el Registro Mercantil en que estuviera inscrita. Efectuado el depósito, el registrador comunicará al registrador mercantil central, para su inmediata publicación gratuita en el 
"Boletín Oficial del Registro Mercantil", el hecho del depósito y la fecha en que hubiere tenido lugar.

De la legislación española cabe resaltar que se concibe la obligación de publicar en el sitio web de las páginas de ambas sociedades durante el plazo de un mes contabilizado desde la toma del acuerdo. A diferencia de la legislación peruana que solo señala la puesta a disposición de la información, en este sistema se obliga a los administradores a informar eficazmente (entiéndase que, en este mundo globalizado, informar mediante la Web es de suma eficacia) y durante un plazo razonable del proyecto de fusión.

Asimismo, el artículo $42^{\circ}$ de la LME concibe la posibilidad de no realizar la publicación cuando el acuerdo se haya tomado por decisión unánime; sin embargo, no exime al administrador del deber de informar a los representantes de los trabajadores. En ese sentido, el inciso 2 del artículo 42 de la LME señala que:

“(..) 2. Los derechos de información de los representantes de los trabajadores sobre la fusión, incluida la información sobre los efectos que pudiera tener sobre el empleo, no podrán ser restringidos por el hecho de que la fusión sea aprobada en junta universal".

Respecto al derecho de los representantes de los trabajadores como sujetos que tienen derecho a obtener la información relacionada en el artículo 39 de la Ley de Modificaciones Estructurales, Uría (2008) afirma que: "la norma mercantil equipara a accionistas y representantes de los trabajadores en cuanto a la forma de hacer efectivo este derecho" (p.14).

Por otro lado, en la normativa laboral, el artículo 44 del Real Decreto Legislativo 1/1995, de 24 de marzo, por el que se aprueba el texto refundido de la Ley del Estatuto de los Trabajadores ("Estatuto de los Trabajadores"), regula que el cambio de titularidad no extingue la relación laboral quedando el nuevo empresario subrogado en los derechos y obligaciones laborales y de seguridad social del anterior empleador.

Conforme lo señala Uría (2008) "el artículo 44.8 del Estatuto de los Trabajadores establece un sistema de información participativa de carácter previo a la modificación subjetiva" (p.15). En el segundo párrafo señala como regla para los supuestos concretos de fusión y escisión de sociedades: "el cedente y el cesionario habrán de proporcionar la indicada información, en todo caso, al tiempo de publicarse la convocatoria de las juntas generales que han de adoptar los respectivos acuerdos".

En relación con la segunda de las cuestiones planteadas, el artículo 44.8 del Estatuto de los Trabajadores establece una obligación genérica de entrega de información que debe realizarse con "suficiente antelación, antes de la realización de la transmisión".

En segundo lugar, respecto a las herramientas brindadas por la legislación española, el artículo 44 de la LME señala que, dentro del plazo de un mes:

Los acreedores de cada una de las sociedades que se fusionan cuyo crédito hubiera nacido antes de la publicación del proyecto de fusión en la página web de la sociedad o del depósito del mismo en el Registro Mercantil, podrán oponerse a la fusión hasta que se les garanticen los créditos.

Asimismo, en consonancia con lo expuesto por Bermúdez (2015), es importante precisar que el artículo se refiere al acceso que tienen los acreedores al acuerdo y al balance de fusión una vez publicados. Por otro lado, conforme se señala líneas arriba, la misma Ley en su artículo $39^{\circ}$ señala el derecho (...) de los representantes de los trabajadores a acceder a la información documental preparatoria del acuerdo de fusión; sin señalar a los acreedores.

Al respecto, cabe preguntar si ¿pueden interpretarse de manera unitaria los arts. $39^{\circ}$ y $40^{\circ}$ de la LME de manera que se pueda entender que, tanto los sujetos señalados como beneficiarios del derecho de información como los que ostentar el derecho de oposición, puedan hacer uso, goce y disfrute tanto del derecho a la información como a oponerse?

La respuesta merece un análisis exegético, buscando establecer cuál es la razón de ser la norma; así pues, si la intención del legislador hubiese sido la de equiparar a los sujetos de la oposición con los del derecho a la información, no entendiéndose el motivo para hacer referencia a un listado de aquellos que tienen derecho 
al acceso la documentación preparatoria del acuerdo de fusión y otro artículo referente a quiénes tienen derecho a la oposición. En síntesis, se considera que el derecho a la oposición opera únicamente respecto a los acreedores comerciales.

Como conclusión del presente acápite, se tiene que los trabajadores inmersos en un proceso de fusión se encuentran más protegidos en la legislación española que en la peruana. En principio, se reconoce el derecho a la información específicamente en el proceso de fusión tanto en la normativa laboral como comercial; mientras que en la legislación peruana ni la normativa laboral hace referencia al traspaso de trabajadores ni a la fusión. Por otro lado, respecto a las herramientas otorgadas a los trabajadores para hacer valer sus acreencias laborales, se entiende que el derecho a la oposición, tanto en Perú como en España, operan a favor de los acreedores comerciales; mientras que, el inicio del proceso concursal puede darse, también, por acreedores laborales; sin embargo, esta posibilidad se reduce debido a los requisitos exigidos por ley.

\subsection{Propuesta Legislativa}

En función de los argumentos previamente manifestados, se propone la modificación de los siguientes artículos de la LGS con la finalidad de salvaguardar los derechos económicos y de información de los trabajadores.

\subsubsection{Modificación 1}

Texto actual artículo 347 LGS: Contenido del proyecto de fusión

“El proyecto de fusión contiene:

\section{$(\ldots)$}

9. Los informes legales, económicos o contables contratados por las sociedades participantes, si los hubiere;

(...)
Propuesta de norma: Contenido del proyecto de fusión

“El proyecto de fusión contiene:

\section{(...)}

9. Los informes legales, económicos o contables contratados por las sociedades participantes, como mínimo el informe referente a la situación laboral de los trabajadores de la sociedad fusionada por absorción o creación;

\subsubsection{Modificación 2}

Texto actual Artículo 350 LGS: Requisitos de la convocatoria

Desde la publicación del aviso de convocatoria, cada sociedad participante debe poner a disposición de sus socios, accionistas, obligacionistas y demás titulares de derechos de crédito o títulos especiales, en su domicilio social los siguientes documentos: (...)

\section{Propuesta de norma Artículo 350: Requisitos de la convocatoria}

Desde la publicación del aviso de convocatoria, cada sociedad participante debe poner a disposición de sus socios, accionistas, obligacionistas y demás titulares de derechos de crédito o títulos especiales, en su domicilio social los siguientes documentos: (...)

Cada sociedad participante debe brindar a los representantes de los trabajadores una copia de la información antes mencionada, publicar en todos los centros de labores el proyecto de fusión desde la publicación del aviso de convocatoria y notificar a los trabajadores personalmente a través del correo institucional o en el domicilio consignado en el contrato de trabajo. 


\subsubsection{Modificación 3}

Texto actual artículo $358^{\circ}$ : Contenido de la escritura pública

La escritura pública de fusión contiene:

1. Los acuerdos de las juntas generales o asambleas de las sociedades participantes;

2. El pacto social y estatuto de la nueva sociedad o las modificaciones del pacto social y del estatuto de la sociedad absorbente;

3. La fecha de entrada en vigencia de la fusión;

4.- La constancia de publicación de los avisos prescritos en el artículo 355; y,

5- Los demás pactos que las sociedades participantes estimen pertinente.

Propuesta de norma artículo $358^{\circ}$ : Contenido de la escritura pública

La escritura pública de fusión contiene:

1. Los acuerdos de las juntas generales o asambleas de las sociedades participantes;

2. El pacto social y estatuto de la nueva sociedad o las modificaciones del pacto social y del estatuto de la sociedad absorbente;

3. La fecha de entrada en vigencia de la fusión;

4. La constancia de la publicación de los avisos prescritos en el artículo 350 y 355;

5. Los informes de las deudas laborales, los convenios tripartitos laborales, el estado contable; $y$,

6.- Los demás pactos que las sociedades participantes estimen pertinentes.
La justificación para incluir dentro del Contenido de la Escritura Pública la notificación regulada en el artículo 350 es la necesidad de protección que ostentan los trabajadores ante cualquier situación de desventaja; en específico, frente al proceso de fusión y el manejo de la información que afecta de forma directa al trabajador

A pesar de no regularse en el ordenamiento jurídico peruano la posibilidad de oposición de los trabajadores a la fusión, estos tienen el derecho a recibir la información suficiente y necesaria para conocer el destino de su relación laboral sobre todo porque esta es de naturaleza alimentaria.

Ahora bien, resulta lógico cuestionar el porqué de la inclusión de las constancias de notificación y publicación del artículo 350 en el contenido de la Escritura Pública de fusión. El motivo fundamental es la inscripción del acto, lo único que se inscribirá en los Registros Públicos y será de conocimiento público es la Escritura Pública de fusión; y, teniendo en cuenta el principio de publicidad este será de conocimiento para todos los acreedores presentes y futuros.

\section{El convenio tripartito laboral como herramienta jurídico empresarial laboral.}

\subsection{Nociones Generales del Convenio Tripartito}

El convenio tripartito se presenta como alternativa de solución jurídico - empresarial; en el cual intervienen la persona jurídica empleadora primigenia (Empleador 1), la persona jurídica que asumirá la titularidad de empleador una vez culminado el proceso de fusión (empleador 2) y el trabajador traspasado (en caso no cuente con sindicato), el sindicato o los representantes de los trabajadores expresamente designados. Para establecer la validez de esta alternativa, se propone analizar los pro y contras que ofrecen, tanto a empleadores como trabajadores (organizados como sindicato o individualmente), la posibilidad de negociar respecto a los derechos laborales (sean adquiridos o por adquirir).

Según Vera (2015) el Convenio Tripartito consiste en un:

Acuerdo privado que tiene como objeto regular las condiciones societario - laborales del traspaso del personal de una empresa hacia la otra. Como su nombre lo indica, este documento se firma por tres 
partes: (1) la empresa que transfiere al personal o "Empresa A"; (2) la empresa que contratará a todo este personal transferido o "empresa B"; y, (3) el trabajador transferido, quien al momento de la firma del convenio tomará conocimiento de las nuevas regulaciones de sus relaciones laborales y de aquellas que se mantienen gracias al respaldo jurídico del principio de continuidad (p.125).

Como primera cláusula, se propone una explicación resumida de los motivos que dieron lugar a la fusión. Esta es sumamente útil debido a que los tres intervinientes "formalizarán su conformidad con la razón que justificó esta operación" (Vera, 2015, p.126); asimismo, se evita que las empresas realicen fusiones de manera fraudulenta y eludan sus responsabilidades; a esta la denominaremos "cláusula introductoria".

Conforme a lo desarrollado en la presente tesis, las condiciones laborales es uno de los temas más controvertidos; por lo tanto, es fundamental que se regulen en el convenio. Específicamente, "debe quedar establecida: 1) la fecha de ingreso del trabajador en la nueva empresa, 2) el reconocimiento de la antigüedad del trabajador traspasado y 3) la titularidad de los pasivos asumidos como consecuencia del traspaso" (Vera, 2015, p. 126); a estas las denominaremos "cláusulas básicas".

Respecto a la fecha de ingreso del trabajador a la nueva empleadora, en virtud del principio de continuidad, la relación laboral continúa siendo la misma desde el empleador primigenio; por lo tanto, la fecha de ingreso a la nueva empresa resulta importante para términos contables, mas no para derechos adquiridos. Es decir, no existe ningún corte en la relación laboral, simplemente se sustituye el empleador; sujeto fungible debido a que su prestación es monetaria. Asimismo, todos los beneficios obtenidos por el trabajador en la primera empresa continúan pese al cese formal y se continúa computando los mismos desde su ingreso a la nueva empresa (Agreda, 2010).

En ese mismo sentido, a los trabajadores traspasados se les deberá contabilizar el tiempo de servicios desde el inicio de la relación laboral celebrada con su empleador primigenio; con la finalidad de contabilizar el tiempo de servicios. En consecuencia, para determinar ciertos derechos (entiéndase derechos laborales con contenido económicos) deberá contabilizarse todo el periodo laborado por el trabajador durante el vínculo laboral con ambas empresas.

Sobre la titularidad de los pasivos asumidos como consecuencia del traspaso, cabe mencionar que no existe en nuestro ordenamiento ninguna disposición que determine estrictamente quién debe asumir las cargas laborales del trabajador traspasado. Para Vera (2015), "en principio, debe ser el empleador primigenio respecto a la primera fase de la contratación, toda vez que éste fue quien contrató al trabajador inicialmente (p. 126)".

Contrariamente a la postura asumida por Vera, se considera que, en virtud del principio de continuidad y la característica de transferencia del patrimonio a título universal y en bloque de la fusión, la titularidad de las deudas laborales, después de la fusión es la sociedad absorbente o creada. Teniendo en cuenta el principio de continuidad, el tiempo de servicios adquirido que será trasladado a la empresa absorbente o creada debería ser asumido por el nuevo empleador.

Las respuestas otorgadas a cada condición que deberá regularse, no es concluyente. En principio, de conformidad con la opinión de Culqui (2015) la transmisión debería respetar las mismas condiciones laborales que mantenía el trabajador en la empresa anterior, a través del aseguramiento de la misma remuneración y la misma categoría laboral, pudiendo haber una mejora en las condiciones de trabajo, pero no un menoscabo en las mismas, evitando así que se utilice esta figura para evadir las normas laborales. Sin embargo, se admite la reducción de la remuneración y la negociación respecto a ciertos derechos laborales adquiridos y a la titularidad de los pasivos previo a la fusión.

Dependiendo del tipo de acuerdo que se asuma, y de la situación económica de cada una de las empresas, es perfectamente posible que la empresa que recibe al trabajador sea quien se encargue de compensar toda su antigüedad anterior, así como el nuevo récord generado en la última empresa. Del mismo modo, es factible que ambas partes puedan establecer si las obligaciones laborales deben ser regularizadas al momento de la suscripción del convenio, o al término de toda la relación laboral en forma definitiva. La única 
condición, en cualquier caso, es que se respete la antigüedad del trabajador, conforme lo hemos explicado líneas arriba, y que se haya pactado por escrito en este convenio tripartito.

Pese a que el trabajador goza de protección especial (principio de continuidad) ante el proceso de fusión societaria, el nuevo empleador tiene la facultad de dirección en su vertiente de ius variandi. Por lo tanto, el nuevo empleador podría modificar ciertas condiciones no esenciales (la labor en sí misma no podría ser objeto del ius variandi; es decir, si prestas el servicio de ingeniero residente, no podría unilateralmente modificarse la labor a contador); siempre y cuando sea razonable, existan razones justificadas y su modificación no afecte sustancialmente al trabajador.

Finalmente, en lo referente a las cláusulas que debe contener el convenio tripartito, podrá pactarse el fijarse una jurisdicción específica ante problemas jurídicos; más no una referente a renunciar al derecho de accionar judicialmente respecto a sus derechos laborales. En virtud del principio de irrenunciabilidad de derechos y al principio protector; cualquier renuncia a accionar judicialmente resulta nula.

\section{Conclusiones}

La fusión empresarial es aquella forma de reorganización societaria que permite a las personas jurídicas concentrar su patrimonio en una nueva sociedad o una constituida regulada en la LGS. En esta se establece un procedimiento específico para su celebración que se caracteriza por salvaguardar los derechos de los acreedores y los socios, pero no los derechos laborales de los trabajadores inmersos en el proceso de fusión. Sin embargo, esto no significa que estos queden desprotegidos, pues en virtud del principio de continuidad laboral, los trabajadores deben conservar las mismas condiciones laborales y el tiempo de servicios laborado; debido a que estamos frente a una sustitución de empleador, siendo, por tanto, la misma relación laboral antes y después de la fusión. Pese a que la relación laboral se encuentra salvaguardada por el principio de continuidad, existe déficit en las relaciones laborales traspasadas respecto a los derechos laborales con contenido económico y el derecho a la información de los trabajadores traspasados.

Respecto a la protección de los derechos laborales con contenido económico y la conservación de derechos y condiciones laborales de los trabajadores traspasados consecuencia de un proceso de fusión se propone la regulación opcional de la suscripción del convenio tripartito toda vez que resulta beneficiosa tanto para el empleador como trabajadores. Para el primero, es útil pues pese a generar costos, estos son razonables ya que se esclarecen los costos laborales y se genera un clima laboral óptimo. Para los segundos, se benefician pues esclarece la protección de sus derechos laborales con contenido económico y el tiempo de servicios adquirido. Finalmente, es beneficioso para ambos ya que, bajo el principio de autonomía de la voluntad en consonancia con el principio de irrenunciabilidad de derechos, se podrá negociar entre trabajador y empleador las condiciones y derechos laborales. En lo referente a la protección del derecho a la información de los trabajadores traspasados a través de un proceso de fusión se propone modificar los artículos 347, 350 y 358 de la LGS (1998). Específicamente, se enfatiza en el deber de brindar la información a los trabajadores en forma efectiva, directa y eficaz.

\section{Bibliografía}

Agreda, J. (2010). Los principios laborales en la jurisprudencia constitucional. Lima, Perú: RAE Jurisprudencia.

Arce, E. (2015). Metodología de regulación de los grupos de empresa en el Derecho individual de Trabajo, en Sociedad Peruana de Derecho del Trabajo y de la Seguridad Social. Primera Edición. Primer Encuentro Peruano-Chileno-Uruguayo de Derecho de Trabajo, (237-251). Lima, Perú: editorial Sociedad Peruana de Derecho del Trabajo y de la Seguridad Social.

Arce, E. (2017). Puntos críticos sobre el cambio de titularidad de la empresa. Revista Laborem, volumen $\mathrm{N}^{\circ}$ 3, pp. 103-115.

Bermúdez, Julio. (2015). El derecho de oposición de los acreedores en la fusión de sociedades mercantiles. Revista Lex Mercatoria, (1), 114-117 http://revistas.innovacionumh.es/index.php?journal=le xmercatoria\&page=article\&op=view\&path\%5B\%5D=85 4\&path\%5B\%5D=79 
Carrillo, M. (2011). La estabilidad de entrada y de salida como expresiones del principio de continuidad. Una aproximación desde la jurisprudencia del Tribunal Constitucional Peruano. Revista Latinoamericana de Derecho Social, (12), 179-186. Recuperado de https://www.redalyc.org/articulo.oa?id $=42964026700$ -

Culqui (27 de marzo de 2015). El Principio de continuidad a la luz del Tribunal Constitucional. [Mensaje en un blog]. Recuperado de http://www.yatacoarias.com/tag/principio-decontinuidad-laboral/

Elías, E. (2015). Derecho Societario Peruano: la Ley General de Sociedades. Lima, Perú, Gaceta Jurídica.

Fabra, J y Spector, E. (2015). Enciclopedia de Filosofía y Teoría del Derecho. Recuperado de https://archivos.juridicas.unam.mx/www/bjv/libros/8/ 3876/25.pdf

García, A. (2010). ¿Cómo se están aplicando los principios laborales en el Perú? Lima, Perú: Soluciones Labores.

Goñi, J. (2014). Los derechos fundamentales inespecíficos en la relación laboral individual: ¿necesidad de una reformulación? https://academica.unavarra.es > bitstream > hanD Lege > Jose Luis Goñi

Kresalja, B. y Ochoa C. (2012). El régimen económico de la Constitución de 1993. Lima, Perú: Fondo Editorial PUCP.

Medina, I. (2016), Efectos de la Transmisión de Empresa en la Relación Laboral. Más allá de la aplicación del principio de continuidad. Revista Derecho \& Sociedad (46), 129-138.

Montoya, U. (2004). Derecho Comercial. Lima, Perú, Grijley,

Morales, A. (1991). Cambios en el titular de la empresa: transformaciones, fusión y escisión. Revista Peruana de Derecho de la Empresa, N³7, T. II, Lima.

Neves, J. (2003). Introducción al Derecho Laboral. Lima, Perú: Fondo Editorial de la PUCP

Ormeño, M. (2006). El uso fraudulento de la persona jurídica. Revista Universidad de Lima, volumen ( $\left.\mathrm{N}^{\circ} 4\right)$, pp. 261-294. Recuperado de
http://repositorio.ulima.edu.pe/bitstream/hanD Lege/ulima/5549/Ormeno Mercedes.pdf?sequence=1 \&isAllowed $=y$

Ortiz, M. R. (2017). El derecho a la libertad de expresión e información en Perú, Bolivia y Colombia desde la perspectiva de la jurisprudencia de la Corte Interamericana de Derechos Humanos, Anuario de Derecho Constitucional Latinoamericano, (XXIII) 533 553, Recuperado de http://perso.unifr.ch/derechopenal/assets/files/articul os/a 20181108 03.pdf

Pacheco, L. (2015). Los principios del Derecho del Trabajo. En J. Zavala (Ed.), Libro homenaje a Mario Pasco Cosmópolis, (pp. 589-607). Lima: Sociedad Peruana de Derecho del Trabajo y la Seguridad Social.

Pasco, M. (2012). Los derechos laborales inespecíficos. Revista Chilena De Derecho Del Trabajo Y De La Seguridad Social, (3) 5, 13-26. Recuperado de https://revistas.uchile.cl > index.php > RDTSS > article > download

Plá, A. (1998). Los principios del Derecho del Trabajo. Buenos Aires, Argentina: ediciones Depalma.

Podetti, H. (2016). Principios del Derecho del Trabajo. Revista UNAM, 139-153 http://biblioteca.cejamericas.org/bitstream/hanD Lege/2015/1194/losprincipiosdelderechodeltrabajo.pd f? sequence $=1$ \&isAllowed $=y$

Rojas Miño, I. (2015). Los grupos de empresas en el sistema jurídico laboral. En Sociedad Peruana de Derecho del Trabajo y de la Seguridad Social. Primera Edición. Primer Encuentro Peruano-Chileno-Uruguayo de Derecho de Trabajo, (253-375). Lima, Perú: editorial Sociedad Peruana de Derecho del Trabajo y de la Seguridad Social.

Sanchez, C. (2005). Derecho Comercial. Lima, Perú: Gaceta Jurídica.

Sanchez, F y Sanchez - Calero. (2005). Instituciones del Derecho Mercantil. Navarra, España: Thomson.

Toledo, C y Toledo, T. (2012). Consecuencias laborales de la fusión de empresas. Abril 2012, Actualidad Jurídica, Volumen (Na 256). Recuperado de http://www2.congreso.gob.pe/sicr/biblioteca/Biblio C 
on.nsf/999a45849237d86c052577920082c0c3/405989 4F1C36BA9A05257B6C0054049D/\$FILE/ASESORIALAB ORAL256.PDF

Toyama, J. (2001). El principio de irrenunciabilidad de derechos laborales: normativa, jurisprudencia y realidad. Revista lus et Veritas, (22), 164-179.

Toyama, J. (2015). El tratamiento jurídico de las reestructuraciones empresariales en el Derecho Laboral peruano (pp. 129-152). Lima, Perú, Sociedad Peruana de Derecho del Trabajo y de la Seguridad Social (SPDTSS).

Tsuboyama, L. (2014). Due diligence laboral: Herramienta imprescindible en las fusiones y adquisiciones. Dialnet, (65), 259-267. Recuperado de https://dialnet.unirioja.es/servlet/articulo?codigo=510 $\underline{4435}$

Uría, O. (2008). Fusión de sociedades, Comentario al régimen legal de las sociedades mercantiles, Madrid, España: Civitas.

Vera, A (2015). Implicancias del traspaso de trabajadores en casos de reorganización societaria. Revista Derecho \& Sociedad, $\mathrm{N}^{\circ}$ 46, pp. 121-127. Recuperado de http://revistas.pucp.edu.pe/index.php/derechoysocied ad/article/viewFile/18825/19045\} 